\title{
Combined Technology of Electro-Spark Alloying and Thermal Diffusion Boriding of Steel
}

\author{
Vladimir Dashkevich \\ Belarusian National Technical \\ University \\ Minsk, Belarus \\ Vladimir_dvl@tut.by \\ Victor Ivashko \\ Belarusian National Technical \\ University \\ Minsk, Belarus \\ vsivashko@bntu.by
}

\begin{abstract}
The process of thermal diffusion boriding is well known and used throughout the world. It has a number of unique properties, such as high hardness and wear resistance under abrasive wear conditions. Continuous boride layers have increased brittleness, which is related with the elastic properties of borides. In this work, we studied the features of the formation of surface layers onlow-carbon steels after electro-spark alloying, and not by continuous processing of the entire surface of the steel, but only sections and subsequent thermal diffusion boriding from powder medium. Such complex technology enables to form discrete regular and irregular layers, which have a number of advantages, in particular, reduced brittleness. The structure and phase composition of the combined coating growth kinetics of the diffusion layer during the thermal diffusion boriding, are investigated. The creation of the considered composite layers with $\mathrm{FeB}$ and $\mathrm{Fe}_{2} \mathrm{~B}$ phases with reduced brittleness will significantly expand their area of application, for example, for working conditions with moderate impact loads.
\end{abstract}

\section{Keywords-Electro-spark, boriding, steel.}

\section{INTRODUCTION}

Currently accumulated a wealth of scientific and practical experience in the application of boriding. Traditionally, the diffusion layer after boriding consists of two phases: on the outer surface of the product there is a high-boron $\mathrm{FeB}$ phase, below a low-boron $\mathrm{Fe}_{2} \mathrm{~B}$, and then a transition zone, represented by a solid solution of boron in $\alpha-\mathrm{Fe}[1,2]$. In addition, between the diffusion layer and the base can form an intermediate layer of cementite (borocementite), which is formed when carbon is pushed back into the product. One of the main problems of boride layers retaining their active use - increased brittleness. The brittleness of boride layers is studied in numerous works, for example, in the works of Krukovich [3]. Traditional ways to reduce the brittleness of the layer are: additional alloying of the layer, obtaining single-phase layers, softening heat treatment, obtaining boride eutectics, etc. Along with them, an effective technique for improving the performance of a thermal diffusion boride layer is to change its morphology, to obtain a discrete structure using surface pretreatment [4].

In this paper, we consider a variant of the combined treatment consisting in preliminary electro-spark alloying (ESA) and subsequent thermal diffusion boriding.

\section{Materials AND METHODS}

When applying ESA coatings, the ENPOUR-121 installation (Russia) was used, the electrode material technical copper. Processing parameters: current I $<0.5$ A; voltage $\mathrm{U}=220 \mathrm{~V}$; vibration frequency $10 \ldots 20 \mathrm{~s}^{-1}$ (turbo mode). After applying the electro-spark coating, thermal diffusion boriding in a powder medium was carried out during furnace heating, in an airtight container with a fusible bolt. Processing mode: temperature $920^{\circ}$ $\mathrm{C}$, time $1 \mathrm{~h}$.

For carrying out the process, an electric shaft furnace with residential heaters is used. As a saturating mixture, the powder environment developed by the Belarusian National Technical University was used, which was obtained by the metal-thermal method of the BestoBor brand (Belarus). The saturating medium used gives special competitive advantages of the boriding enhancement technology.

Metallographic studies of the samples obtained after processing were carried out on a Leica microscope with magnification from 200 to 500 times. Microstructural studies were performed on transverse microsections, etched in special metallographic reagents. Microhardness measurements were performed on a PMT-3 instrument with loads of $0.49 \mathrm{~N}$ and $0.98 \mathrm{~N}$.

\section{RESULTS AND DISCUSSION}

When combining two technological processes of hardening, it is necessary to take into account the materials used and the resulting structures. For the case under consideration, the coatings formed during the electric-spark treatment can be divided into two groups: 
1 - coatings that intensify the diffusion process of the element, in our case boron, and 2 - barrier coatings that partially or completely suppress the diffusion process of the element into the interior of the product. The most promising direction of the combination of the combination under consideration is the possibility of obtaining regular coatings consisting of boride sections isolated from each other by fragments of an electric spark coating. Therefore, in this paper, we considered the case of barrier coatings, in particular, steel samples obtained by ESA copper electrode.

During the formation of areas of boride needles separated from each other by fragments of another coating obtained, for example, ESA, there is a partial compensation of elastic deformations in the layer due to adjacent zones and, as a consequence, a decrease in brittleness.

The specificity of the electric-spark processing makes it possible to simply form the processing not of the entire surface, but of sections, for example, forming a periodic (regular) profile in the form of lines parallel to each other. Moreover, the step between the treatment sites can vary widely, contributing to the formation of layer structures of different morphology. In our case, the distance between the areas treated by ESA was about $2 \mathrm{~mm}$ (fig. 1). By varying the pitch and modes of the preliminary electricspark treatment, the prerequisites for controlling the layer structure are created.

Thus, processing performed by the following scheme:

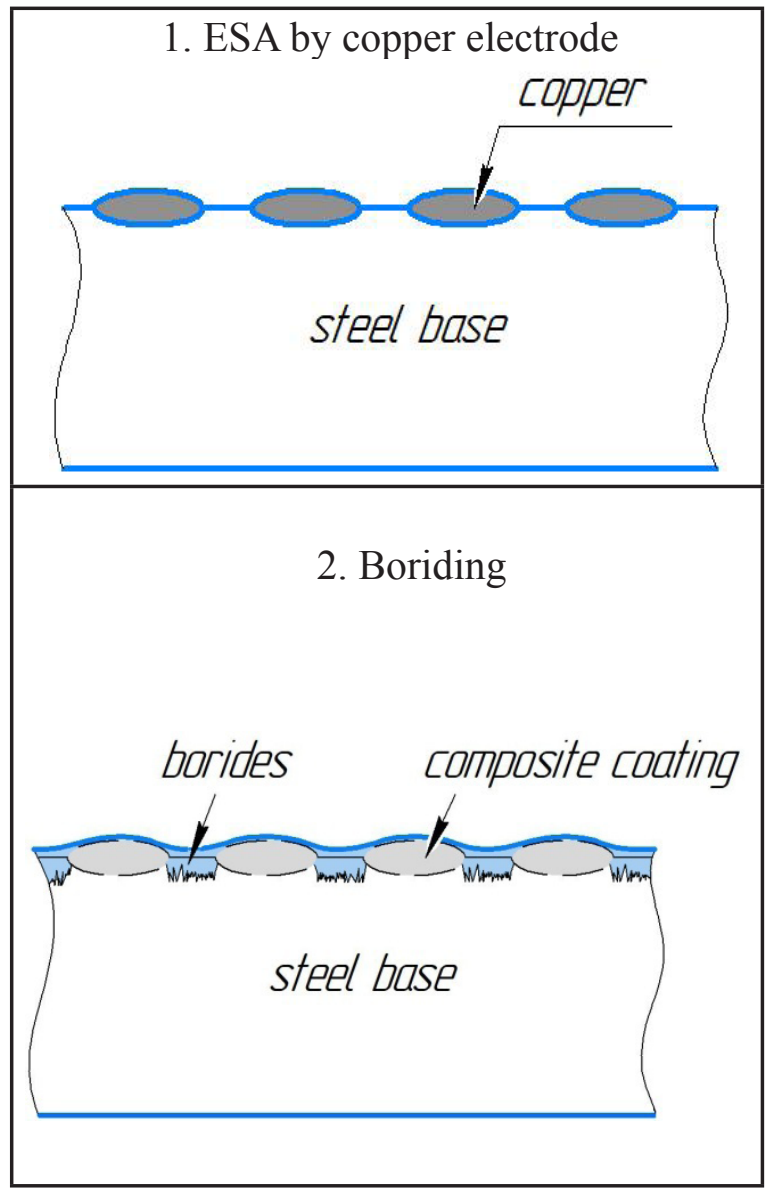

Fig. 1. Scheme of coating obtaining with a combination of ESA and boriding
As noted earlier, copper was chosen because it prevents the through diffusion of boron. It is known that boron does not form compounds with copper, and the solubility of boron in copper is extremely low $(0.06 \% \mathrm{wt}$.) [5]. When copper is applied by the ESA method, sparking occurs on the surface and part of the copper electrode is transferred to the surface, while copper partially mixes with the base metal, a defective structure is formed, which is only partially impermeable to boron atoms [6]. During the subsequent boriding, a conglomerate of iron and copper borides is formed, and the borides are mainly represented by the low-boron phase $\mathrm{Fe}_{2} \mathrm{~B}$ (fig. 2).

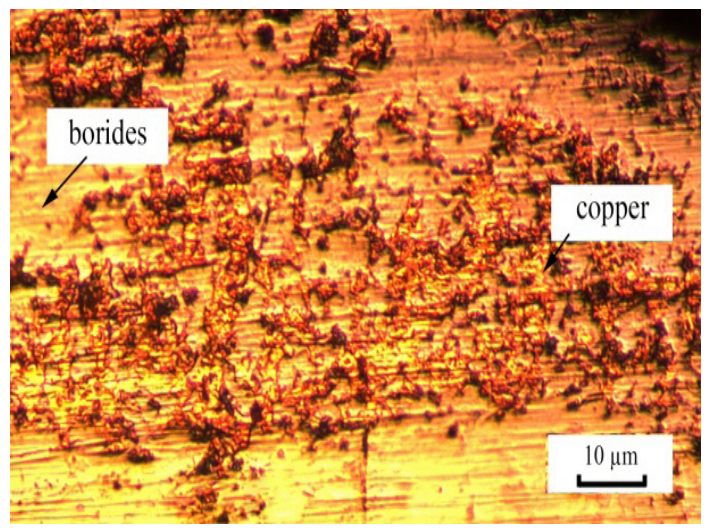

Fig. 2. The microstructure of the area with a composite coating, obtained by preliminary copper ESA

As a result of complex processing structure formed with distinct areas of classical boride layer and the areas of the composite coating formed by preliminary copper ESA (fig. 3).

It should be noted that the transition zone of the two areas of the structure is quite sharp. The microhardness of the boride area is $14000-15000 \mathrm{MPa}$, the area of composite coating varies in wide range from 1500 to $1400 \mathrm{MPa}$.

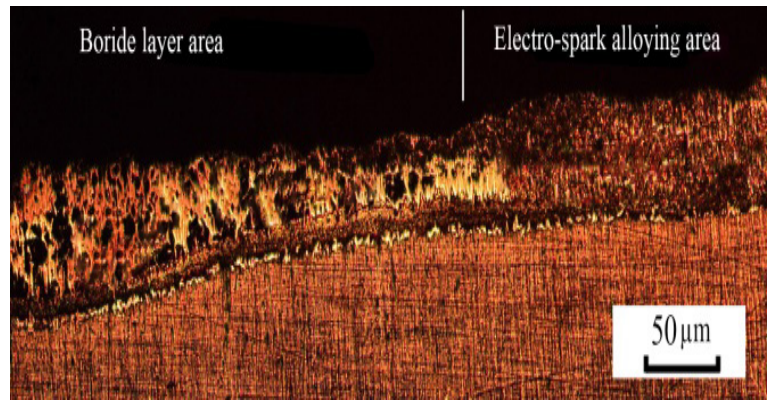

Fig. 3. Microstructure of the coating consisting of a boron layer and a composite coating

The application of the copper coating by the method of ESA contributes to the separation of the total layer during the subsequent boriding to the areas of the boride layer and the areas of the composite coating based on iron and copper borides. Moreover, copper in the structure is represented as separate dispersed inclusions with sizes of about 5 ... 20 microns (fig. 2). Such structure is sufficient and promising for parts working in friction pairs, in this case copper can partially act as a lubricant.

It has been established that the microhardness of the 
obtained boride areas corresponds to the microhardness of the layers obtained under the classical processing conditions, including in the zone approaching the transition, and is $14000-15000 \mathrm{MPa}$.

One of the most important criteria that is crucial for the effective use in production is the fragility of the obtained thermal diffusion layers. Obviously, the resulting structure of the diffusion layer will reduce brittleness and a tendency to shear at high contact pressures and shock loads $[3,7]$.

The characteristic of brittleness was evaluated by the cleavage stress, as well as the total score of brittleness.

The cleavage stress is an integral characteristic of the fragility of the layer, spontaneously taking into account the physical and mechanical properties of the borides themselves, the phase composition, the phase ratio, their dispersion and mutual arrangement in the layer and on the surface, the stress state of the layer and its plasticity. The greater the value of the cleavage stress, the less brittleness, and therefore the layer is more plastic [3, 8].

The brittleness score was determined based on the microhardness measurement method. This characteristic is a qualitative indicator of fragility and is similar to the method used to assess the fragility of nitrided layers.

As a result of investigations it was found that the brittleness of the considered complex coating is reduced. The brittleness determined in areas with a composite layer structure, determined by the cleavage stress, is reduced in 1.5 times relative to traditional boriding (table 1).

TABle I. Characteristic Of Brittles

\begin{tabular}{|c|c|c|}
\hline \multirow{2}{*}{ Processing type } & \multicolumn{2}{|c|}{ Brittleness rate } \\
\cline { 2 - 3 } & $\begin{array}{c}\text { Cleavage } \\
\text { stress, MPa }\end{array}$ & $\begin{array}{c}\text { The total score of } \\
\text { brittleness Z100 }\end{array}$ \\
\hline Boriding (two-phase) & 280 & 35 \\
\hline ESA +boriding & 420 & 26 \\
\hline
\end{tabular}

Note that there is no clear correlation between the values of brittleness in certain different ways, but the general trends for all research options remain.

\section{CONCLUSIONS}

Thus, the application of a copper coating by the ESA method enables the separation of the total layer during the subsequent boriding to the zone of the boride layer and the zone of composite coating. In areas with a composite coating obtained by preliminary ESA, boron diffusion slows down, due to which lower iron borides are predominantly formed, which have a higher ductility. Due to the appearance of copper inclusions in the structure, in which the elastic modulus is much less than that of borides, some reduction and relaxation of internal stresses in the layer is possible, which affects the overall brittleness of the boride layer.

The creation of the considered binary composite layers based on boron can significantly reduce the fragility of the resulting layers and, accordingly, expand their area of application, for example, for working conditions with moderate impact loads.

\section{REFERENCES}

[1] LG. Voroshnin, L.S. Lyakhovich, Boronizing of Steel, Metallurgy, Moscow, 1978 (in Russian).

[2] M. Kulka, Current trends in boriding: Techniques: Springer Nature, Switzerland, 2019.

[3] Krukovich M.G., Prusakov B.A, Sizov I.G. Plasticity of Boronized Layers: Springer International Publishing AG, Switzerland, 2016.

[4] M.A. Béjar, W. Schnake, W. Saavedra J.P. Vildósola, Surface hardening of metallic alloys by electrospark deposition followed by plasma nitriding, Journal of Materials Processing Technology 176 (1-3), pp. 210-213. June 2006.

[5] O.A. Bannyh, M.E. Drica, Phase diagrams of binary and multicomponent iron-based systems: A Handbook, Moskow: Metallurgy, 1986 (in Russian).

[6] A.E. Gitlevich, V.V. Mikhailov, N.Ya. Parkansky, V.M. Revutskiy, Electrospark alloying of metal surfaces, Chisinau: Shtiintsi Publishing House, 1985 (in Russian).

[7] C. H. Xu, Wei Gao,Y.L. Yang, Superplastic boronizing of a low alloy steel - microstructural aspects, Journal of Materials Processing Technology. Vol. 108 (3), pp. 349-355, Jan. 2001.

[8] V. F. Protasevich, V. V. Melnichenko, Some features of microhardness and micro-brittleness of boride layers, Journal of Foundry Production and Metallurgy. Vol. 4 (36), pp. 145-147, 2005 (in Russian). 